\title{
Use of MRSA surveillance data for infection control: individual units rather than entire hospital as the basis for improvement
}

\author{
P Gastmeier ${ }^{1 *}$, F Schwab ${ }^{2}$, I Chaberny ${ }^{3}$, C Geffers ${ }^{1}$ \\ From International Conference on Prevention \& Infection Control (ICPIC 2011) \\ Geneva, Switzerland. 29 June - 2 July 2011
}

\section{Introduction / objectives}

To analyze which surveillance system (a hospital based or a unit based) leads to a greater decrease in incidence density of nosocomial MRSA.

\section{Design}

Two cohort studies of surveillance data.

\section{Setting}

Two MRSA surveillance components exist within the German national nosocomial infection surveillance system KISS: one for the whole hospital (i.e. only hospital based data and no rates for individual units) and one for ICU-based data (rates for each individual ICU).

\section{Participants}

Data from a total of 224 hospitals and 359 ICUs in the period from 2004 to 2009.

\section{Methods}

Development over time was described first for both surveillance systems. In a second step only data were analyzed from those hospitals/ICUs with continuous participation for at least four years. Incidence rate ratios (IRR) with 95\% confidence intervals were calculated to compare incidence densities between different time intervals.

\section{Results}

In the baseline year the mean MRSA incidence density of hospital acquired MRSA cases was 0.25 and the mean incidence density of ICU-acquired MRSA was 1.25 per
1000 patient days. No decrease in hospital-acquired MRSA rates was found in a total of 111 hospitals with continuous participation in the hospital- based system. However, in 159 ICUs with continuous participation in the unit-based system, a significant decrease of $29 \%$ in ICU-acquired MRSA was identified.

\section{Conclusion}

A unit-based approach of surveillance and feedback seems to be more successful in decreasing nosocomial MRSA rates, compared to a hospital-based approach.

\section{Disclosure of interest}

None declared.

\section{Author details}

${ }^{1}$ Institute of Hygiene and Environmental Medicine, Berlin, Germany. ${ }^{2}$ CHARITÉ - University Medicine Berlin, Berlin, Germany. ${ }^{3}$ Institute of Medical Microbiology and Hospital Epidemiology, Hannover Medical School, Hannover, Germany.

Published: 29 June 2011

\section{doi:10.1186/1753-6561-5-S6-P13}

Cite this article as: Gastmeier et al:: Use of MRSA surveillance data for infection control: individual units rather than entire hospital as the basis for improvement. BMC Proceedings 2011 5(Suppl 6):P13. 